\title{
Light Tar Decomposition of Product Pyrolysis Gas from Sewage Sludge in a Gliding Arc Plasma Reformer
}

\author{
Mun Sup Lim, Young Nam Chun $^{\dagger}$ \\ BK21 Team for Hydrogen Production, Department of Environmental Engineering, Chosun University, Gwangju 501-759, Korea
}

\begin{abstract}
Pyrolysis/gasification technology utilizes an energy conversion technique from various waste resources, such as biomass, solid waste, sewage sludge, and etc. to generating a syngas (synthesis gas). However, one of the major problems for the pyrolysis gasification is the presence of tar in the product gas. The tar produced might cause damages and operating problems on the facility. In this study, a gliding arc plasma reformer was developed to solve the previously acknowledged issues. An experiment was conducted using surrogate benzene and naphthalene, which are generated during the pyrolysis and/or gasification, as the representative tar substance. To identify the characteristics of the influential parameters of tar decomposition, tests were performed on the steam feed amount (steam/carbon ratio), input discharge power (specific energy input, SEI), total feed gas amount and the input tar concentration. In benzene, the optimal operating conditions of the gliding arc plasma 2 in steam to carbon (S/C) ratio, $0.98 \mathrm{kWh} / \mathrm{m}^{3}$ in SEI, $14 \mathrm{~L} / \mathrm{min}$ in total gas feed rate and $3.6 \%$ in benzene concentration. In naphthalene, $2.5 \mathrm{in} \mathrm{S/C}$ ratio, $1 \mathrm{kWh} / \mathrm{m}^{3}$ in SEI, $18.4 \mathrm{~L} / \mathrm{min}$ in total gas feed rate and $1 \%$ in naphthalene concentration. The benzene decomposition efficiency was $95 \%$, and the energy efficiency was $120 \mathrm{~g} / \mathrm{kWh}$. The naphthalene decomposition efficiency was $79 \%$, and the energy yield was $68 \mathrm{~g} / \mathrm{kWh}$.
\end{abstract}

Keywords: Benzene, Gliding arc plasma, Naphthalene, Sewage sludge pyrolysis, Tar

\section{Introduction}

Environmentally friendly and more efficient methods to produce energy are currently under intense research and development. Pyrolysis/gasification technology is an energy conversion technique, which produces syngas (synthesis gas) from various waste resources, such as biomass, solid waste, organic sewage sludge, and etc. However, tar is generated during the pyrolysis or gasification process. The tar is a hydrocarbon compound, which can be easily condensed under an ambient condition, and is consisted of aromatic compounds having benzene rings [1, 2]. Especially, condensed tar can cause corrosion problem from an organic acid and generates obstacle in pipelines. This will hinder the maintenance and operation of the facility.

Tar removal technology can be divided into in-pyrolysis gasifier technology (IPGT) and technology after pyrolysis gasifier (TAPG). The IPGT does not require additional facility for tar removal, and adopts the improvement in the operating conditions and gasifier design technology. Through these researches, production of syngas, with low tar concentratiom, should be achieved, but numerous limitations, such as facility scale-up, and installation of expensive and complex thermal decomposition gasifier, are remained $[3,4]$.

The TAPG can be broadly categorized into physical and chem- ical methods $[1,5,6]$. The physical methods employ wet scrubber, cyclone, filter, wet electrostatic precipitator, and adsorption tower. The chemical methods employ catalytic and thermal cracking, partial oxidation, and plasma reactors. The wet scrubbing has been widely used for tar removal, but wastewater has to be treated in order to avoid environmental pollution, using a large plant, and this incurs a relatively high cost. The catalysts are extremely sensitive to the contaminants, such as sulfur, chlorine, and nitrogen compounds, generating in gasification of biomass. Also, they can get deactivated due to coke formation, and high cost should be considered during its usage at high temperatures.

As an alternative to this, basic study on low temperature pulsed plasma for tar removal has been conducted to resolve the formation of tar, during the biomass pyrolysis. Compared to the conventional thermal and catalytic cracking, plasma discharge shows the higher removal efficiency, due to the formation of radicals. However, high cost of preparation of pulse power supply and short life cycle is the key for improvement [7].

A gliding arc discharge has been utilized for the hydrogen rich gas production from fossil fuel and biogas, and for decomposition of volatile organic compounds (VOCs), and shows a greater potential, compared to the others. It is widely acknowledged to be more commercial for reforming and VOCs reduction [8-11]. However, there is almost no gliding arc discharge applied to tar (c) This is an Open Access article distributed under the terms of the Creative Commons Attribution Non-Commercial License (http://creativecommons. org/licenses/by-nc/3.0/) which permits unrestricted non-commercial use, distribution, and reproduction in any medium, provided the original work is properly cited.
Received January 12, 2012 Accepted May 18, 2012

${ }^{\dagger}$ Corresponding Author

E-mail: ynchun@chosun.ac.kr

Tel: +82-62-230-7872 Fax: +82-62-230-7156 


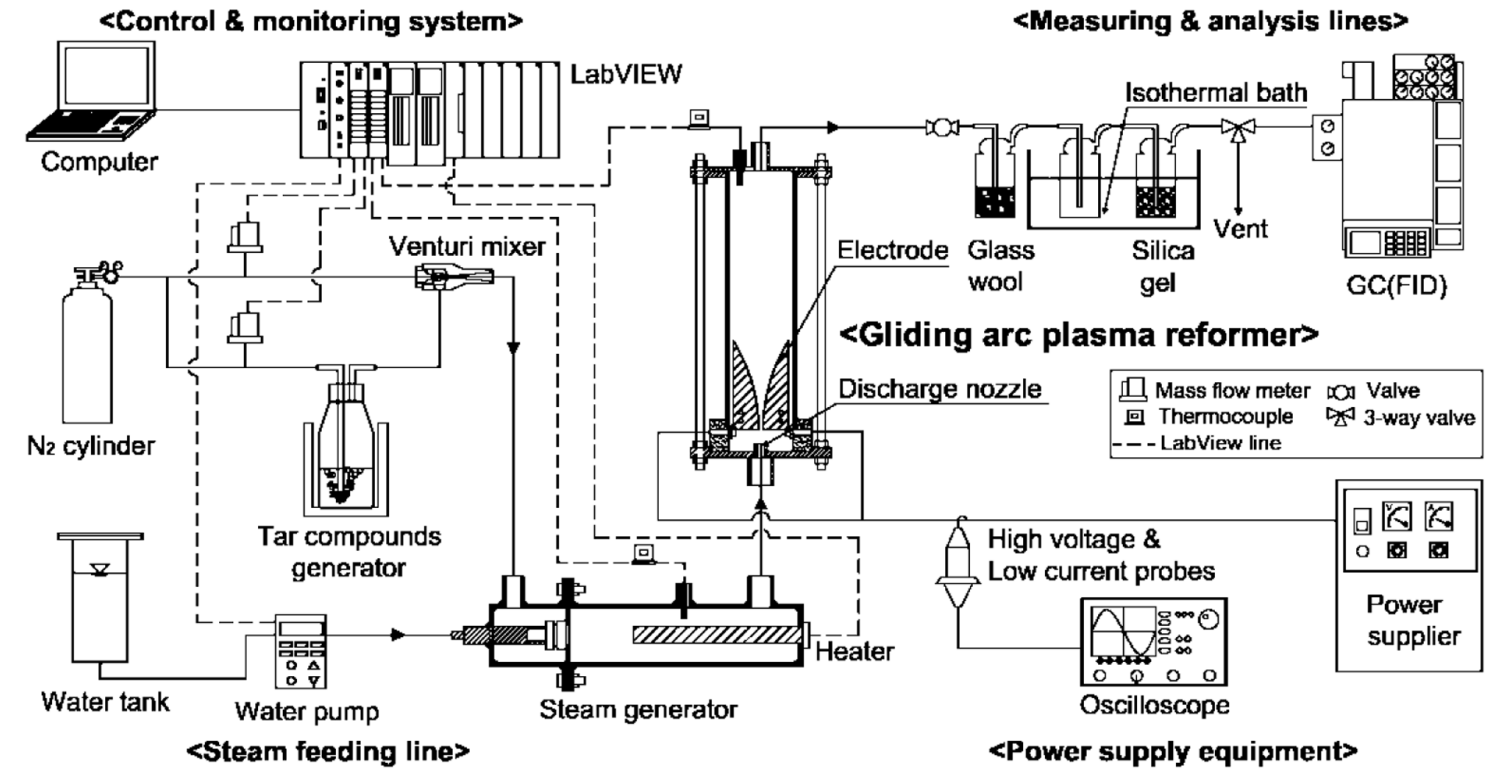

Fig. 1. Schematic diagram of an experimental setup.

removal in product pyrolysis gas.

As major features, it is easy to control the operating conditions and has high decomposition efficiency for tar destruction, along with high energy efficiency. Therefore, it should be accepted as a new alternative method with feature of environmentfriendliness.

In this study, a gliding arc plasma reformer was developed for the decomposition of tars in the product pyrolysis gas. In addition, the benzene and naphthalene were selected as major tar compounds in the pyrolysis gasification of the sewage sludge, and was tested with parameters that could effect the decomposition efficiency of the tars and energy efficiency.

\section{Materials and Methods}

\subsection{Experimental Apparatuses}

Fig. 1 shows a schematic of experimental setup for tar compound decomposition test. The experimental setup consisted of a gliding arc plasma reformer, steam feeding line, power supply equipment, measuring and analysis line, and a control and monitoring system.

The gliding arc plasma reformer consisted of a quartz cylinder (55 $\mathrm{mm}$ in diameter and $200 \mathrm{~mm}$ in length) to see the inside and for insulation, having three diverging knife-shaped electrodes in 120 degrees. The electrodes length was $95 \mathrm{~mm}$, and gap distance between electrodes was $3 \mathrm{~mm}$. An electrode support was made of ceramic $\left(\mathrm{Al}_{2} \mathrm{O}_{3}\right.$ weight $\left.96 \%\right)$ for fixation and insulation of the electrodes. A gas injection nozzle was set on the ceramic plate, and the diameter of the nozzle was $1.5 \mathrm{~mm}$.

The steam feeding line consisted of a steam generator and a water pump. For the steam supply, distilled water in the water tank is fed by the water pump (STEPDOS03; KNF, Balterswil, Switzerland). The feed water should be changed to steam in the steam generator. The water pump controls the steam amounts.

The power supply equipment consisted of a power supplier
(UAP-15K1A; Unicorn Tech., Anyang, Korea) and an electric instrument, having a high voltage probe (P6015; Tektronix, Beaverton, OR, USA) and a low current probe (A6303; Tektronix) with an oscilloscope (TDS-3052; Tektronix). The power supplier supplies 3 phases of alternating current (AC) to the plasma reformer, and the electric instrument determines an electric power by measuring the voltage and current in the two probes.

The measuring and analysis line consisted of sampling line, including a glass wool bottle, a silica-gel bottle and an analyzer, including a gas chromatography (GC-14B; SHIMADZU, Kyoto, Japan) with FID detector and capillary column (J\&W DB-1, 15 m x 0.25 mm I.D., 0.25 um; Agilent Technologies, Palo Alto, CA, USA).

The control and monitoring system consisted of a LabVIEW 8.6 (National Instrument, Austin, TX, USA) and a computer. The LabVIEW monitors the temperatures in each part, and controls water pump, heater of steam generator, and nitrogen gas flow rate.

\subsection{Experimental Method}

The nitrogen in a $\mathrm{N}_{2}$ cylinder was fed through the dilution line to purge the plasma reformer. The tar compound generator and steam generator were heated up to the setting temperature, respectively. Also, nitrogen was fed through the feeding line, and water was fed through the water pump to the steam generator. After stabilizing the temperature for each part, the experiments were achieved, as shown in Fig. 2. Sampling of tar compound was made at the sampling port, located on the inlet and outlet. Soot and water in the sampling gas were removed at glass wool and silica gel bottles. The dried gas sample was entered to flame ionization detector (FID) injection port of the gas chromatograph for gas analysis. Analysis condition of the gas chromatograph was maintained as $200^{\circ} \mathrm{C}$ for the injector and $280^{\circ} \mathrm{C}$ for the detector. Oven temperature is raised from $40^{\circ} \mathrm{C}$ to $320^{\circ} \mathrm{C}$ at $10^{\circ} \mathrm{C} /$ $\mathrm{min}$, and stabilization status is analyzed for the next $20 \mathrm{~min}$.

As parametric experiments, steam feed amount (steam to 


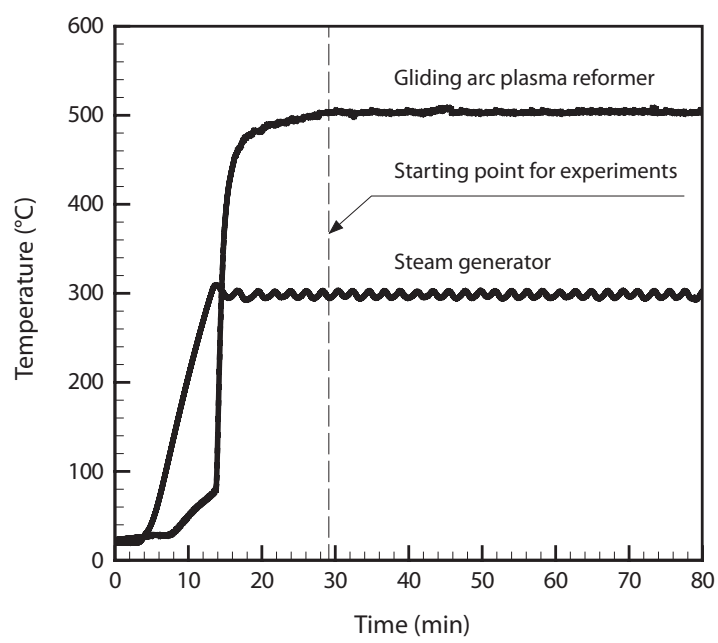

Fig. 2. Initial operating and stable conditions in the plasma reformer.

carbon ratio, S/C ratio), input discharge power (specific energy input, SEI), total feed gas amount, input tar concentration were selected as factors that can impact on tar decomposition efficiency. The range of variables is shown in Table 1, including the optimum case.

Tar decomposition efficiency showing the degree of tar destruction, among the feed gas is calculated according to Eq. (1) [12].

$$
\eta_{\mathrm{t}}(\%)=\frac{[\mathrm{VC}]_{\text {inlet }}-[\mathrm{VC}]_{\text {exhaust }}}{[\mathrm{VC}]_{\text {inlet }}} \times 100
$$

where, $[\mathrm{VC}]_{\text {inlet }}$ is the input tar concentration (\%), and $[\mathrm{VC}]_{\text {exhaust }}$ is the tar output concentration (\%).

Equation for energy efficiency of the reformer is shown in Eq. (2) (i.e., mass of tar removed per unit energy consumed) [12].

$$
\eta_{\mathrm{e}}\left(\mathrm{gkW}^{-1} \mathrm{~h}^{-1}\right)=\frac{[\mathrm{MC}]_{\mathrm{removal}} \times \mathrm{Q}}{\mathrm{IP}}
$$

where, $[\mathrm{MC}]_{\text {removal }}$ is the removal tar concentration $\left(\mathrm{g} / \mathrm{m}^{3}\right), \mathrm{Q}$ is the total gas flow rate $\left(\mathrm{m}^{3} / \mathrm{h}^{1}\right)$, and IP is the input electric power for plasma discharge $(\mathrm{kW})$.

SEI is denoted as the ratio of input electric power, and a total gas flow rate, and is shown in Eq. (3) [12].

$$
\operatorname{SEI}\left(\mathrm{kWh} / \mathrm{m}^{3}\right)=\frac{\mathrm{IP}}{\mathrm{Q}}
$$

SEI was varied from 0.26 to $1.58 \mathrm{kWh} / \mathrm{m}^{3}$ by controlling the power ranging from 0.22 to $1.33 \mathrm{~kW}$.

Carbon balance, which represents the carbon mass, as follows in Eq. (4) [13].

Carbon balance $(\%)=\frac{[\mathrm{CO}]+\left[\mathrm{CO}_{2}\right]+2\left[\mathrm{C}_{2} \mathrm{H}_{4}\right]+2\left[\mathrm{C}_{2} \mathrm{H}_{6}\right]+3\left[\mathrm{C}_{3} \mathrm{H}_{8}\right]}{\mathrm{A}\left([\mathrm{VC}]_{\text {inlet }}-[\mathrm{VC}]_{\text {exhaust }}\right)} \times 100$

where [CO], $\left[\mathrm{CO}_{2}\right],\left[\mathrm{C}_{2} \mathrm{H}_{4}\right],\left[\mathrm{C}_{2} \mathrm{H}_{6}\right]$, and $\left[\mathrm{C}_{3} \mathrm{H}_{8}\right]$ are the concentrations of each ingredient (\%), and $\mathrm{A}$ is the carbon constant. (i.e., benzene $=6$, naphthalene $=10$ )

\section{Results and Discussion}

In this study, a gliding arc plasma reformer for tar destruction, among the pyrolysis product gas from sewage sludge was developed. For this purpose, tar compounds were tested according to test conditions. Experimental conditions and optimal conditions are shown in Table 1. The experimental conditions in each parameter were taken for test rages, maintaining a stably plasma discharge. The optimal case was the conditions showing the maximum tar decomposition and energy efficiencies, and the results are presented in Table 2. For benzene, the decomposition efficiency and energy efficiency were $95 \%$ and $120 \mathrm{~g} / \mathrm{kWh}$, respectively. In addition, carbon balance showed $98 \%$. For naphthalene, the decomposition efficiency, energy efficiency, and carbon balance were $79 \%, 68 \mathrm{~g} / \mathrm{kWh}$, and $99 \%$, respectively.

The light gases that were produced from the benzene and naphthalene decomposition included $\mathrm{H}_{2}, \mathrm{CO}$, and $\mathrm{CO}_{2}, \mathrm{C}_{2} \mathrm{H}_{4}$, $\mathrm{C}_{2} \mathrm{H}_{6}, \mathrm{C}_{3} \mathrm{H}_{8}$. In addition, the carbon balance did not reach $100 \%$ because the heavy hydrocarbon, nitric tar products (HCN and $\mathrm{CN}$ ), the carbon black, and etc., from the benzene and naphthalene conversion products, were not considered [14].

Table 1. Experimental conditions for parametric studies and optimum cases

\begin{tabular}{|c|c|c|c|c|c|c|c|c|c|}
\hline \multirow{2}{*}{ Result } & \multicolumn{6}{|c|}{ Gas composition after the reformer $\left(\%, \mathrm{~N}_{2}\right.$ excluded) } & \multirow{2}{*}{$\begin{array}{c}\text { Carbon } \\
\text { balance } \\
(\%)\end{array}$} & \multirow{2}{*}{$\begin{array}{l}\text { Tar decomposition } \\
\text { efficiency }(\%)\end{array}$} & \multirow{2}{*}{$\begin{array}{c}\text { Energy efficiency } \\
(\mathrm{g} / \mathrm{kWh})\end{array}$} \\
\hline & CO & $\mathrm{CO}_{2}$ & $\mathrm{C}_{2} \mathrm{H}_{4}$ & $\mathrm{C}_{2} \mathrm{H}_{6}$ & $\mathrm{C}_{3} \mathrm{H}_{8}$ & $\mathbf{H}_{2}$ & & & \\
\hline Benzene & 20.4 & 32.4 & 7.2 & 12.1 & 8.1 & 19.5 & 98 & 95 & 120 \\
\hline Naphthalene & 13.4 & 50.8 & 1.2 & 4.8 & 6.0 & 23.7 & 99 & 79 & 68 \\
\hline
\end{tabular}

\begin{tabular}{lcccccc}
\hline \multirow{2}{*}{ Conditions } & \multicolumn{2}{c}{ Benzene } & & \multicolumn{2}{c}{ Naphthalene } \\
\cline { 2 - 3 } \cline { 5 - 6 } & Test case & Optimum case & & Test case & Optimum case \\
\hline Steam/Carbon ratio & $0.6-6$ & 2 & & $1.2-4.5$ & 2.5 \\
Specific energy input $\left(\mathrm{kWh} / \mathrm{m}^{3}\right)$ & $0.26-1.58$ & 0.98 & & $0.77-1.17$ & 1.00 \\
Total gas flow rate $(\mathrm{L} / \mathrm{min})$ & $7-28$ & 14 & & $10.5-27.6$ & 18.4 \\
Input tar concentration $(\%)$ & $1.4-7$ & 3.6 & & $0.6-1.3$ & 1 \\
\hline
\end{tabular}

Table 2. Experimental results at the optimum conditions 

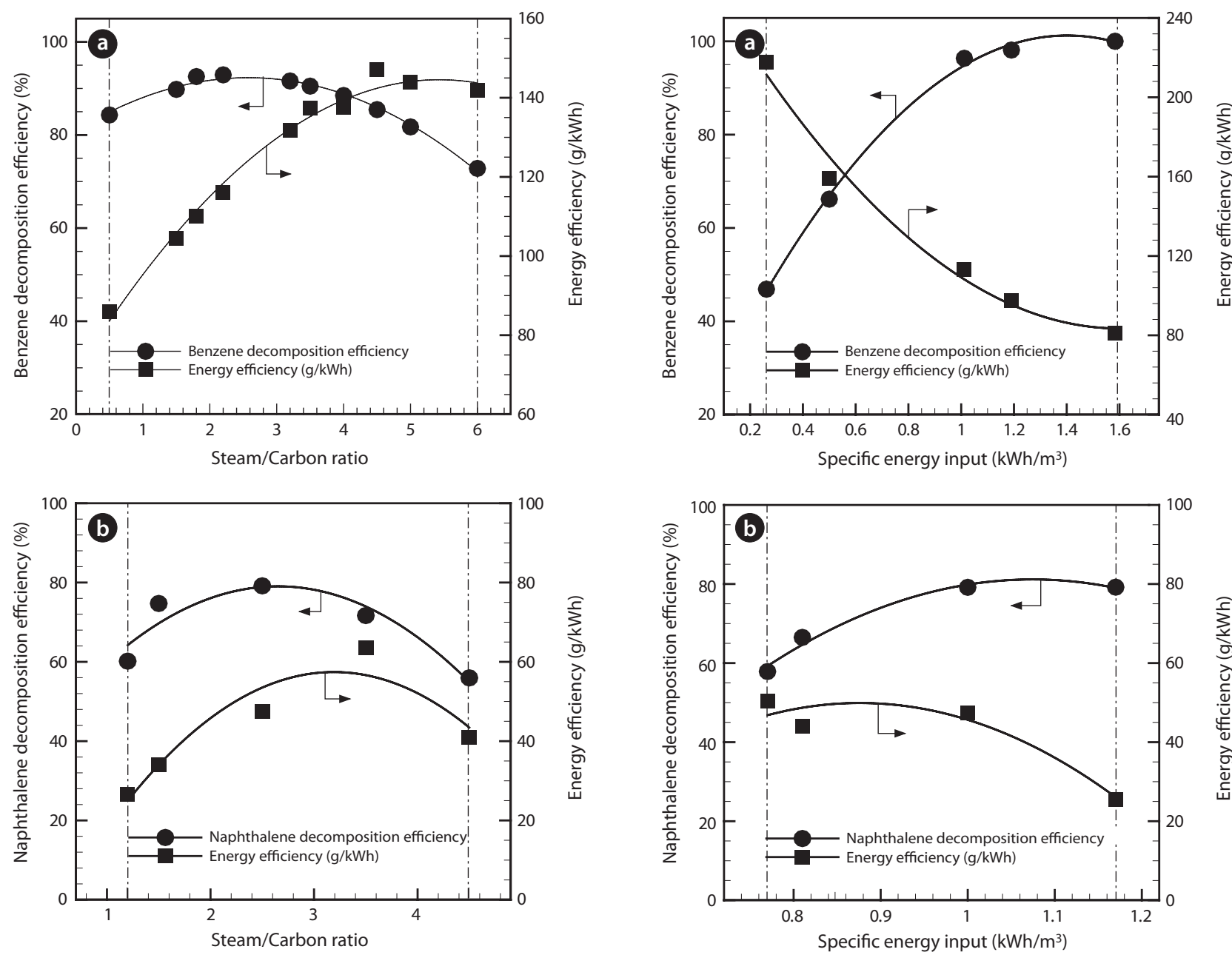

Fig. 3. Effect of steam/carbon ratio. (a) Benzene, (b) naphthalene.

\subsection{Effect of Steam Feed Amount}

Fig. 3 shows the tar decomposition efficiency and energy efficiency by the change of steam feed amount ( $\mathrm{S} / \mathrm{C}$ ratio). The carbon black formed at less than the specific value of $\mathrm{S} / \mathrm{C}$ ratio in the plasma reformer. Further, at higher than the specific value of S/C ratio, the temperature decrease of the steam evaporator was noticed from the increased amount of water. Therefore, S/C ratios in these experiments were varied from 0.6 to 6 in the benzene tar, and from 1.2 to 4.5 in the naphthalene tar. Tar decomposition efficiency was gradually increased with S/C ratio, and show the maximum values. After that, those are gradually decreased.

Steam injection on plasma discharge in the reformer leads to the direct formation of hydroxyl radicals $\left(\mathrm{OH}^{*}\right)$, which is generated by the radiolysis of water [15].

$$
\mathrm{H}_{2} \mathrm{O} \rightarrow \mathrm{H}^{+}+\mathrm{OH}^{*}+\mathrm{e}^{-}
$$

Increase in steam, during discharge, shows the increment of hydroxyl radicals, which react with benzene and naphthalene for the destruction. That is why the tar decomposition efficiencies are increased gradually.

However, the steam also has an adverse effect on tar re-

Fig. 4. Effect of specific energy input. (a) Benzene, (b) naphthalene.

moval, due to its electronegative characteristics, as seen in the figures. Too many water molecules limit the electron density in the plasma reformer and quench the activated chemical species [12]. Therefore, controlled humidity is essential for tar decomposition. For the benzene tar, energy efficiency is significantly increased with $\mathrm{S} / \mathrm{C}$ ratio, and slightly decreased after a maximum value of $142 \mathrm{~g} / \mathrm{kWh}$ at 4.5 of $\mathrm{S} / \mathrm{C}$ ratio. For the naphthalene tar, the energy efficiency is raised up to $63 \mathrm{~g} / \mathrm{kWh}$ at $3.5 \mathrm{of} \mathrm{S} / \mathrm{C}$ ratio. After this peak point, the efficiency is decreased gradually. The reason why the energy efficiency in the naphthalene decreases more drastically is that the decrease of naphthalene decomposition was much lower than one of the benzene decomposition.

\subsection{Effect of Input Discharge Power}

Fig. 4 presents the effect of SEI, which is denoted as the ratio of electric input power and feed gas flow rate, and is shown in Eq. (3). Change in SEI was made for $0.26-1.58 \mathrm{kWh} / \mathrm{m}^{3}$ by adjusting the input discharge power on $0.22-1.33 \mathrm{~kW}$. As SEI increases, benzene decomposition efficiency is significantly increased, and shows higher than $90 \%$ after $0.9 \mathrm{kWh} / \mathrm{m}^{3}$ of SEI. Gradual increase in naphthalene decomposition efficiency is exhibited by increasing the SEI, and average $79 \%$ of decomposition efficiency 

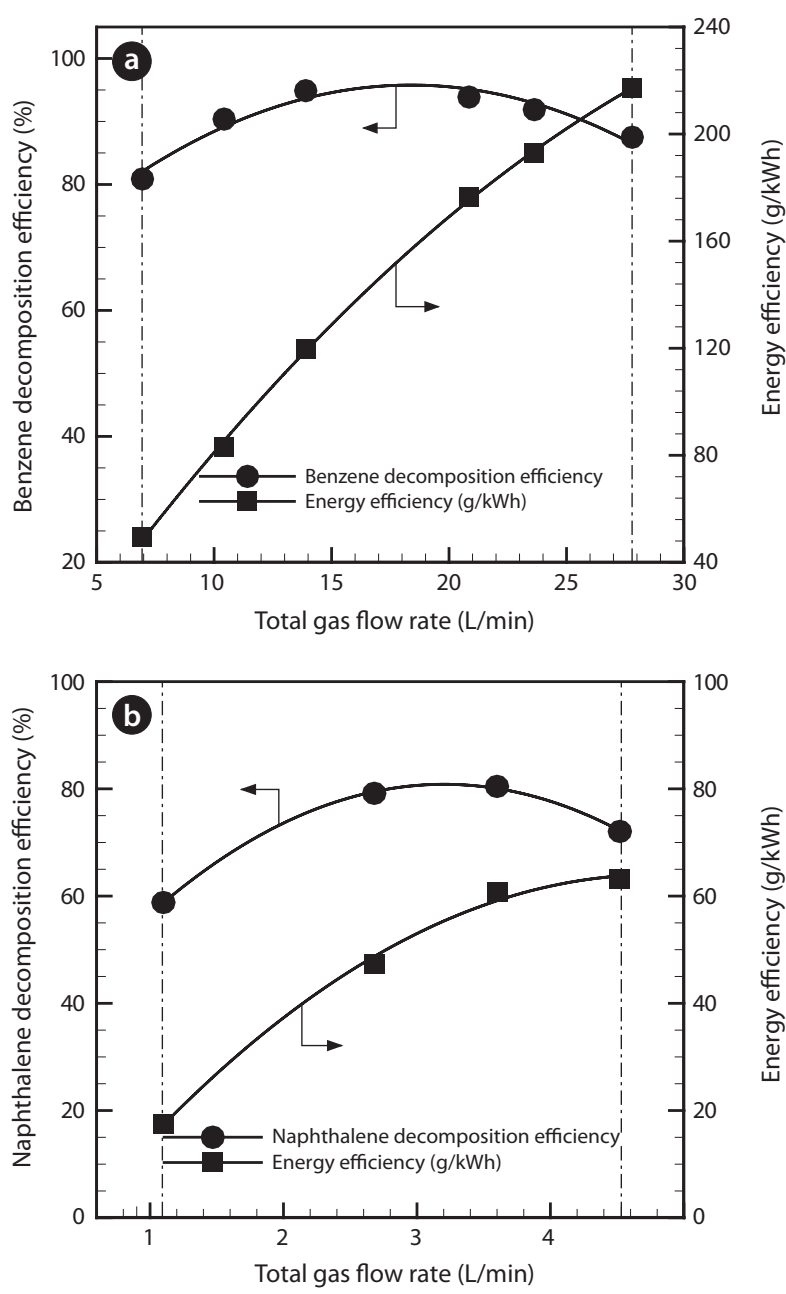

Fig. 5. Effect of total gas flow rate. (a) Benzene, (b) naphthalene.

is achieved at higher than $1 \mathrm{kWh} / \mathrm{m}^{3}$. High power, i.e., high SEI, gives more available electrons to initiate the decomposition of benzene or naphthalene by collision. This is reasonably supported by the fact that the quantity of electric transfer between the electrodes increases with increasing applied voltage with fixed geometry of the electrode [9].

In addition, benzene energy efficiency is decreased from 217 to $81 \mathrm{~g} / \mathrm{kWh}$ along with an increase in the SEI. The energy efficiency of naphthalene is significantly decreased from 50 to $26 \mathrm{~g} /$ $\mathrm{kWh}$. For the plasma reformer developed in this study, relatively high value of both tar decomposition efficiencies and energy efficiencies were achieved, compared to the existing results [11, $16]$.

\subsection{Effect of Total Feed Gas Amount}

Fig. 5 shows the effect of change in total feed gas amount. The total gas amount was controlled within $7-28 \mathrm{~L} / \mathrm{min}$ for benzene or within 10.5-27.6 L/min for naphthalene. The plasma discharge was generated unstably from higher than $7 \mathrm{~L} / \mathrm{min}$ in benzene or $10.5 \mathrm{~L} / \mathrm{min}$ in naphthalene of total feed gas amount. The tar decomposition efficiencies are increased gradually, of up to the maximum values $(95 \%$ at $14 \mathrm{~L} / \mathrm{min}$ of benzene or $79 \%$
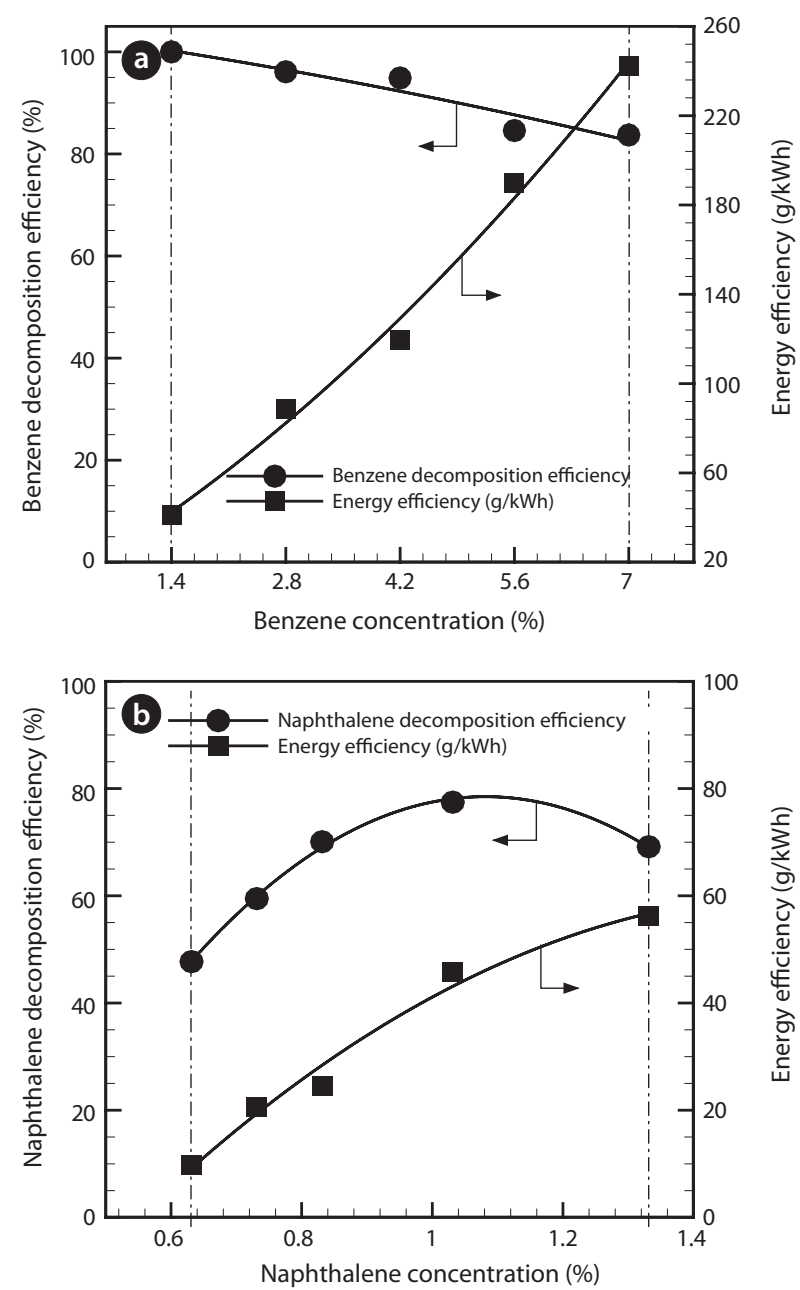

Fig. 6. Effect of input tar concentration. (a) Benzene, (b) naphthalene.

at $18.4 \mathrm{~L} / \mathrm{min}$ of naphthalene). This is because the plasma discharge became stable, and the plasma zone was extended by an increasing gas amount.

However, the tar decomposition efficiency was gradually decreased with increment of total gas feed amount, after the peak points. This is related to the reduction of residence time at the discharging area from the increased gas flow rate. Generally, increase in total gas amount causes a decrease in the tar decomposition efficiencies, regardless of the chemical structure. It is corresponded to the reduced collision of radical electron and reaction ion, due to the short period of interaction time and contact between the plasma discharging area and tars [17]. Energy efficiencies are significantly increased with the total gas feed amount. The energy efficiencies increase, even though the tars decomposition in the reformer decrease after the peak points. It is because the total gas flow rate in Eq. (2) increase, showing higher effectiveness than the decrease of the tar decomposition.

\subsection{Effect of Input Tar Concentration}

Fig. 6 shows the effect of change in its initial tar concentrations for benzene or naphthalene. The input tar concentrations varied from $1.4 \%$ to $7.0 \%$ for benzene, or from $0.6 \%$ to $1.3 \%$ for 
naphthalene. Benzene decomposition efficiency is gradually decreased with increasing input benzene concentration. The reason is that amount of benzene to be decomposed by the plasma discharge at the same SEI should be increased. In general, low input concentration shows higher decomposition efficiency compared to the higher one [11].

But when the input naphthalene concentration was low (up to $1 \%$ ), plasma discharge was made intermittently. Gradual increase in the input concentration ensures the higher naphthalene decomposition efficiency, due to being a better plasma discharge state. Regarding the energy efficiency, an increase in the tar concentrations show the significant increase in the actual processed gas amount because $\mathrm{S} / \mathrm{C}$ ratio is fixed to 2, constantly. Therefore, energy efficiency is increased from 41 to $242 \mathrm{~g} / \mathrm{kWh}$ for benzene or from 12 to $58 \mathrm{~g} / \mathrm{kWh}$ for naphthalene.

\section{Conclusions}

A gliding arc plasma reformer for the tar decomposition, among pyrolysis product gas from sewage sludge, was developed. For this purpose, tar compounds were tested, according to the operating conditions. Optimum case was chosen from the condition (Table 1), which has the maximum value of tar decomposition efficiency and energy efficiency. The benzene decomposition and energy efficiencies were $95 \%$ and $120 \mathrm{~g} / \mathrm{kWh}$, respectively. The naphthalene decomposition and energy efficiencies were $79 \%$ and $68 \mathrm{~g} / \mathrm{kWh}$

As parametric experiments, steam feed amount, input discharge power, total feed gas amount, input tar concentrations were set as variables, and the following results were achieved: 1) Steam feed amounts in both the benzene and naphthalene tars had maximum values in the decomposition efficiency and energy efficiency at the specific S/C ratio; 2) Increment of the input discharge power exhibited a gradual increase in the decomposition efficiency and a decrease in the energy efficiency; 3) Total feed gas amount, at a specific point, showed the maximum decomposition efficiency; and the energy efficiency was significantly increased along with the total gas amount; and 4) Benzene decomposition efficiency was increased slightly with an increasing input benzene concentration. But naphthalene decomposition efficiency was increased, gradually. Energy efficiencies in both tars were significantly increased.

\section{Acknowledgments}

This research was supported by Basic Science Research Program through the National Research Foundation of Korea (NRF) funded by the Ministry of Education, Science and Technology (2010-0004156).

\section{References}

1. Milne TA, Evans RJ, Abatzoglou N. Biomass gasifier "Tars": their nature, formation, and conversion. Golden: National
Renewable Energy Laboratory; 1998. NREL/TP-570-25357.

2. Hasler P, Nussbaumer T. Sampling and analysis of particles and tars from biomass gasifiers. Biomass Bioenergy 2000;18:61-66.

3. Devi L, Ptasinski KJ, Janssen FJ. A review of the primary measures for tar elimination in biomass gasification processes. Biomass Bioenergy 2003;24:125-140.

4. Bergman PC, van Paasen SV, Boerrigter H. The novel "OLGA" technology for complete tar removal from biomass producer gas. In: Expert Meeting on Pyrolysis and Gasification of Biomass and Waste; 2002 Sep 30 - Oct 1; Strasbourg, France.

5. Fjellerup J, Ahrenfeldt J, Henriksen U, Gøbel B. Formation, decomposition and cracking of biomass tars in gasification. Lyngby: Technical University of Denmark; 2005. Technical report: MEK-ET-2005-05.

6. Devi L, Ptasinski KJ, janssen FJ. Pretreated olivine as tar removal catalyst for biomass gasifiers: investigation using naphthalene as model biomass tar. Fuel Process. Technol. 2005;86:707-730.

7. Nair SA, Pemen AJ, Yan K, et al. Tar removal from biomassderived fuel gas by pulsed corona discharges. Fuel Process. Technol. 2003;84:161-173.

8. Yang YC, Lee BJ, Chun YN. Characteristics of methane reforming using gliding arc reactor. Energy 2009;34:172-177.

9. Sreethawong T, Thakonpatthanakun P, Chavadej S. Partial oxidation of methane with air for synthesis gas production in a multistage gliding arc discharge system. Int. J. Hydrog. Energy 2007;32:1067-1079.

10. Chun YN, Song HO. Syngas production using gliding arc plasma. Energy Sources Part A Recovery Util. Environ. Eff. 2008;30:1202-1212.

11. Indarto A, Yang DR, Azhari CH, et al. Advanced VOCs decomposition method by gliding arc plasma. Chem. Eng. J. 2007;131:337-341.

12. Du CM, Yan JH, Cheron B. Decomposition of toluene in a gliding arc discharge plasma reactor. Plasma Sources Sci. Technol. 2007;16:791-797.

13. Kim HH, Oh SM, Ogata A, Futamura S. Decomposition of benzene using Ag/TiO2 packed plasma-driven catalyst reactor: influence of electrode configuration and Ag-loading amount. Catal. Lett. 2004;96:189-194.

14. Cataldo F. Ultrasound-induced cracking and pyrolysis of some aromatic and naphthenic hydrocarbons. Ultrason. Sonochem. 2000;7:35-43.

15. Burlica R, Kirkpatrick MJ, Finney WC, Clark RJ, Locke BR. Organic dye removal from aqueous solution by glidarc discharges. J. Electrostatics 2004;62:309-321.

16. Yu L, Yan JH, Li XD, et al. Naphthalene decomposition by atmospheric gliding arc gas discharge. Proceedings of the 19th International Symposium on Plasma Chemistry; 2009 Jul 26-31; Bochum, Germany. International Plasma Chemistry Society; 2009.

17. Bo Z, Yan J, Li X, Chi Y, Cen K. Scale-up analysis and development of gliding arc discharge facility for volatile organic compounds decomposition. J. Hazard. Mater. 2008;155:494501 . 